\title{
Towards a Tiered or Differentiated Approach to Protection of Traditional Knowledge (TK) and Traditional Cultural Expressions (TCEs) in Relation to the Intellectual Property System
}

\section{Chidi Oguamanam}

Professor, Faculty of Law, University of Ottawa; Senior Fellow, Centre for International Governance Innovation (CIGI), Waterloo, ON, Canada; and Steering Committee Member, Open African Innovation Research (Open AIR) network

\section{iD https://orcid.org/0000-0003-4301-9388}

\begin{abstract}
The World Intellectual Property Organisation (WIPO) has, for nearly two decades, engaged in formulating the nature and content of a text-based legal instrument or instruments for the effective protection of genetic resources (GRs), traditional knowledge (TK), and traditional cultural expressions (TCEs, also known as folklore) within or relating to the international intellectual property (IP) system. This task has been the job of WIPO's Intergovernmental Committee on Intellectual Property and Genetic Resources, Traditional Knowledge and Folklore (IGC), established in 2000. In this article, I explore the context and rationales for, and evolution of, one of the IGC's evolving contributions: development of a tiered or differentiated approach to the protection of TK and TCEs. The article discusses and analyses the empirical ramifications and challenges of the tiered approach-alternatively referred to as differentiated approach — with reference to examples of forms of TK and TCE in Africa, North America and Australia. I conclude that the approach is a work in progress, still evolving, which provides a useful broad policy framework at the international level while, at the same time, its details are contingent on many considerations better addressed at national and local levels.
\end{abstract}

\section{Keywords}

Indigenous Peoples and local communities (IPLCs), genetic resources (GRs), traditional knowledge (TK), traditional cultural expressions (TCEs), tiered or differentiated approach, intellectual property (IP), World Intellectual Property Organisation (WIPO), Intergovernmental Committee on Intellectual Property and Genetic Resources, Traditional Knowledge and Folklore (IGC)

\section{Acknowledgements}

The author acknowledges funding support for this study provided by the Centre for International Governance Innovation (CIGI) through its International Law Research Program (ILRP). This article draws on content from the author's 2018 CIGI research paper (Oguamanam, 2018b). The author takes sole responsibility for any errors or omissions.

DOI: https://doi.org/10.23962/10539/27533 


\section{Recommended citation}

Oguamanam, C. (2019). Towards a tiered or differentiated approach to protection of traditional knowledge (TK) and traditional cultural expressions (TCEs) in relation to the intellectual property system. The African Journal of Information and Communication (AJIC), 23, 1-24. https://doi.org/10.23962/10539/27533

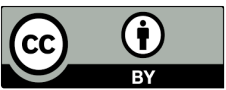

This article is licensed under a Creative Commons Attribution 4.0 International (CC BY 4.0) licence: https://creativecommons.org/licenses/by/4.0

\section{Introduction}

The World Intellectual Property Organisation's (WIPO's) Intergovernmental Committee on Intellectual Property and Genetic Resources, Traditional Knowledge, and Traditional Cultural Expressions (hereafter the "IGC") has an extremely difficult mandate: to negotiate a text-based instrument or instruments for the effective protection of genetic resources (GRs), traditional knowledge (TK), and traditional cultural expressions (TCEs, i.e., folklore) within or relating to the intellectual property system (see WIPO, 2015).

WIPO's jurisdictional status as the host of the IGC is, in part, fallout from the World Trade Organisation's (WTO's) failure to include TK and TCEs in the text of its adjunct Agreement on Trade-Related Aspects of Intellectual Property Rights (TRIPS Agreement). Additionally, WIPO's jurisdiction in this area is a result of the increasing economic and trade importance of GRs, TK and TCEs. Given the longstanding involvement by UNESCO in TK and related matters including TCEs, the jurisdictional ambit of WIPO IGC is, arguably, confined to the IP-related ramifications of GRs, TK and TCEs, even though the protection of these subject matters inherently requires a sui generis approach. Consequently, WIPO Member States and experts are required to ensure and respect synergies between the IPoriented and non-IP-oriented aspects of TK and TCEs as they feature in other regimes.

\section{Enigmatic nature of TK and TCEs}

The core difficulties of the IGC's task are coloured by, but not primarily a function of, the contentious nature of international IP policymaking processes, the international IP system's ubiquitous geopolitical power relations, and ideological schisms over knowledge governance (May \& Sell, 2005; Oguamanam, 2012, p. 35; Raustiala, 2007). Additionally, the difficulties do not principally lie in the institutional dynamics of the WIPO's committee process or in the complex regime ecosystem in which TK and TCEs are engaged (Helfer, 2004; Oguamanam, 2007; Yu, 2007). Without question, 
those factors contribute to making the IGC mandate a Herculean task. ${ }^{1}$ But the most critical difficulties at the heart of the IGC project is the enigmatic nature of TK and, to an even greater extent, TCEs. TCEs have been, and remain, a unified or inherent component of TK. But at WIPO and other forums, attempts have been made to isolate TCEs from TK, in conceptual terms, with TCEs approached as being separate from TK. Regardless, in such contexts, both TK and TCEs are pragmatic, and thus generalised, terms of convenience and compromise-generalised, but yet not able to capture the full breadth of the complexities of (1) relationships and nuances implicated in the experiences of the custodians of TK and TCEs, and (2) the custodians' undergirding worldviews as mediated by their knowledge systems.

The interfaces between TK and innovations in the realms of pharmaceuticals, cosmetics, agriculture, chemicals and environmental conservation, which constitute the core of the "biopiracy" phenomenon, provide pivotal sites in which IP, specifically the patent regime, directly engages TK in contestation over the applications of GRs across different knowledge frameworks. Notwithstanding these examples, the interfaces between IP and TK/TCEs generally tend to be difficult to pin down. In the patent regime, "newness" of TK, analogous to an invention, is a consistently problematic issue (Mgbeoji, 2001). In the area of copyrights, fixation and publication, especially of TCEs, are perennial hurdles (Boateng, 2011; Kuruk, 1999). In respect of trademarks and designs, claims of sacredness-as a basis of exclusion of certain marks, symbols, insignias, or designs from commercial exploitation—remain a source of tension amongst stakeholders (Coombe, 1998a).

\section{Competing interests in the IGC}

For many longtime participants in the IGC, from both developed and developing countries, the lingering delay to reach agreement on anticipated text or texts, after nearly 20 years of work, is disappointing (see Oguamanam, 2017). This disillusionment is especially the case for many Global Southern countries and experts, and for Indigenous Peoples and local communities (IPLCs) from both the Global South and Global North.

However, for many Global Northern WIPO Member States, and for experts from these countries, the IGC's protracted delays are not necessarily seen as disadvantageous (Oguamanam, 2017). Most countries of the Global North, often called nondemandeur countries, participate in IGC negotiations with little or no vested interest in achievement of a codified international legal instrument or instruments for the protection of GRs, TK and TCEs. It was, of course, intemperate appropriation of GRs and associated TK (and even TCEs) by corporate and research entities based in

1 See the Robinson, Abdel-Latif and Roffe (2017) volume for examination of the first decade and a half of the work of the IGC. 
the Global North² (i.e., biopiracy) (see Mgbeoji, 2006; Robinson, 2010)—facilitated largely through the international IP regime, especially the patent system-that, in part, necessitated the establishment of the IGC. Accordingly, countries of the Global North, save for a few, are reluctant participants in the IGC process; ${ }^{3}$ for them, the status quo is desirable (Oguamanam, 2017).

Key negotiating blocs at the IGC who are invested in ensuring that the IGC results in an effective international instrument or instruments pursuant to its mandate, and who thus constitute the demandeurs, are the African Group, the Group of Latin American and Caribbean Countries (GRULAC), and the Asia-Pacific Group (APG). All of the aforementioned liaise, consult, and/or coalesce, as the need arises, under the auspices of the IGC's Like-Minded Countries (LMCs) group. Another key bloc in the demandeur category is the Indigenous Caucus, which is a coalition of accredited Indigenous Peoples' delegations to IGC who cut across geopolitical boundaries.

\section{The study}

The study on which this article is based explored development, in the IGC, of the tiered approach - also referred to as the differentiated approach - to the protection of TK and TCEs pursuant to the IGC's mandate. It is an approach which is subject to ongoing debate and continuing elaborations at the IGC. ${ }^{4}$ (While the mandate of the IGC is to negotiate a text-based instrument or instruments for effective protection of three (often overlapping) sets of phenomena-GRs, TK, and TCEs-the tiered or differentiated approach relates to only two of the phenomena: TK and TCEswhich, it must at the same time be noted, are sites in which IPLCs often deploy GRs.)

In the study, I explored the rationale for the tiered or differentiated approach, and drew on examples from three sites of TK/TCE production-sites in Africa (Ghana), Australia, and North America (US and Canada) - in order to interrogate the approach and its potential and practical applications. The study ultimately found that the tiered or differentiated approach can potentially serve as a useful abroad policy framework operating at international level, but with the details of its operation contingent on considerations at national and local levels, including but not limited to: the specific manifestation of TK or TCE; the dynamics of IPLC customary laws and protocols

2 Often in collaboration with researchers and institutions linked to the Global South, e.g., as was the case in the failed US patent on turmeric (initially granted to WR Grace Inc.), in which US-based Indian researchers were instrumental. See Bala (2011).

3 For some of these countries, their participation takes on a vigilante tenor, which focuses on ensuring that the resulting instrument of instruments does/do not constrain or disrupt the status quo on international IP, especially the patent regime.

4 For an outline of the text of the tiered or differentiated approach to TK, see WIPO (2016b). 
in regard to custody, production, and practices in relation to the manifestation of TK or TCE; and the evidentiary threshold in respect of determining the level of diffusion of a specific manifestation of TK or TCE.

\section{Marginalisation of TK and TCEs from the Conventional IP system}

\section{Colonial narratives}

The industrialised colonial powers showed no inclination to facilitate IPLC protection of TK and TCEs, as evidenced in narratives of colonialism deploying lenses of, among others, science, anthropology, philosophy and critical social sciences (De Sousa Santos, 2007; Oguamanam, 2015). The consensus across these renditions was that, in contrast to the "innovative cultures" of Western (or European) societies (Arewa, 2004; De Sousa Santos, 2007; Memmi, 1990; Mutua, 2011), IPLCs and non-Western societies-positioned as the West's "Other"-were lacking in meaningful innovation (see De Beer, Oguamanam, \& Schonwetter, 2014; De Sousa Santos, 2007; Oguamanam, 2008). These IPLCs and non-Western civilisations were recognised as having substantial endowments of natural resources, ${ }^{5}$ but their dealings with those resources were cast as being mundane and rudimentary, and thus incapable of transforming natural endowments from their so-called "state of nature". Accordingly, the insights, knowledge, and practices of IPLCs and non-Western societies, as applied to natural resources-in, for example, agriculture, medicine, ecology, and environmental stewardship — were adjudged to be lacking the human ingenuity and other criteria necessary for their protection under orthodox, Westernoriginated IP systems (Oguamanam, 2015).

\section{"Public domain" assertions}

Coupled with this denigration of the intellectual value of IPLCs'TK and TCEsamidst compelling evidence to the contrary ${ }^{6}$ - were, and are, assertions from rich, industrialised nations that many of the GRs and indeed broader biological resources

5 It is estimated that over $75 \%$ of global biological resources are found in the Global South and/or in traditional or ancestral habitats utilised by IPLCs. See, for example, Oguamanam (2012).

6 The first symmetric stone tools were invented in Africa. Africa is recognised as the "nest of many discoveries, inventions, creations and cultures" that have since catapulted human civilisations across the globe. In medicines, sciences, and all facets of arts and creativity, African innovations serve as the forerunner of most revolutionary inventions and ideas that have shaped the trajectory of human civilisation. Hero of Alexandria, Egypt invented the first documented steam engine in the 1st century AD. See Elahi and De Beer (2013). Yet, in the colonial worldview, "[h]istorically, Africa is not part of the world; it cannot show evidence of any movement or development. The historic movements it displays - on the Northern region of the continent-belong to the Asian and European world" (Hegel, 1970, quoted by De Sousa Santos, Nunes, and Meneses (2007, p. xxxv)). This narrative or situating of Africa "was the counterpoint of the colonial requirement of transporting civilization and wisdom to peoples who lived in the dark recess of ignorance" (De Sousa Santos et al., 2007, p. xxxv). 
that constitute the pivot for the production of TK, and even TCEs, should be regarded as part of a global "public domain" or "commons". In the words of Okediji (2018):

Armed with legal tools, such as "the common heritage of mankind" and "the public domain", scientists and international institutions facilitated the development of a global knowledge infrastructure for research and innovation, utilizing plant GRs and traditional knowledge. International regimes for science and research coalesced around the view that those resources were part of an uncharted global commons that could - indeed should - be freely and methodically exploited. (Okediji, 2018, pp. 3-4)

Such "public domain", "commons" and "common heritage" constructs, when applied to TK and TCEs, assail attempts to protect TK and TCEs within or in relation to the conventional IP paradigm.

\section{The perspectives of IPLCs}

IPLC custodians of TK and TCEs do not accept the narratives casting their knowledge and practices as lacking in human ingenuity (see Anaya, 2004: De Sousa Santos, 2007). And while TK and TCE custodians and practitioners recognise the importance of a vibrant public domain as a fundamental feature of sustainable knowledge production under the orthodox IP system, their perspective on the public domain is grounded in recognition that several centuries of delegitimation and exploitation have been the primary drivers of their TK and TCEs becoming publicly available and cast as global public goods (Oguamanam, 2018b). ${ }^{7}$

A central matter that has emerged at the IGC is the need to determine the context in which, and/or the degree to which, a given TK or TCE is diffused, or is publicly available such that it constitutes a part of the public domain (or an approximation of the public domain). The need to find ways to make such assessments, which will have to be done on a case-by-case basis, has led to development of the tiered or differentiated approach.

\section{Emergence of the tiered or differentiated approach to TK and TCEs}

\section{7th Session of the IGC, March-April 2014}

At the IGC's 27th Session in Geneva in late March and early April 2014, concerted initiatives by the LMCs group (including the African Group), led to formal documenting of the idea of a tiered or differentiated approach to TK and TCEs (Okediji, 2017). The idea had been explored before the 27th Session, in early March

7 For progressive conceptualisations of knowledge as a global public good, see Stiglitz (1999) and Maskus and Reichmann (2005). 
2014, by an LMC Consultative Meeting in Bali. ${ }^{8}$ At the Bali meeting, the Chair, Ambassador Wayne McCook of Jamaica, had leveraged "the treatment of publicly available and/or widely diffused TK and TCEs" into becoming a key cross-cutting issue for examination of TK and TCEs (McCook, 2014b). McCook then elaborated the issue further in a 51-page "Chair's Non-paper" (McCook, 2014a), helping prompt the deliberations at the IGC's 27th Session (see WIPO, 2014a). Speaking on behalf of the facilitators of the 27th Session, Nicolas Lesieur (Canada) noted that they

[...] had sought to construct a tier-based framework that was itself based on the extent to which the TK was diffused and/or protected by beneficiaries, or not, such that there were different levels of diffusion and protection. (WIPO, 2014a, para. 95)

Accordingly, the concept was articulated in Article 3 of the Draft IGC documents on TK and TCEs that were prepared for the 27th Session (WIPO, 2014b; 2014c).

\section{Aims and characteristics of the approach}

The primary aim of the tiered or differentiated approach is to advance legal certainty and clarity on TK and TCEs in order to allay concerns raised by non-demandeur countries and experts, mainly of the Global North, in the IGC negotiations. The approach provides a framework for delineating different kinds of TK and TCEs based on their degrees of diffusion, or lack thereof. It then seeks to determine the extent of exclusive rights or partially exclusive rights that the TK and TCE custodians could receive, based on how much of the TK or TCE in question, or aspects thereof, is/are diffused or publicly available, as the case may be. The approach is pragmatic and malleable.

While there is notyet a consensual understanding of the approach across IGC delegates, there is wide acceptance of the idea that the approach would not countenance use, or continued use, of any TK or TCE without permission and accountability. Essentially, the approach recognises that some TK and TCEs are already publicly available or diffused, albeit by default through various forms of diffusion and appropriation, some legitimate some not (Oguamanam, 2018a; Okediji, 2017). As such, according to the approach, where the TK or TCE is already in the public domain or publicly available, there should not be ex post facto attempts, especially in regard to the former situation, to force the genie inside the bottle, i.e., to take the TK or TCE out of the public

8 For more detailed insight, see the official report of the IGC's 27th Session (WIPO, 2014a). In addition to the 2014 Bali LMCs Consultative Meeting, the history of the idea of a differentiated approach to TK is not complete without reference to the international consultative meeting of experts organised by the Government of India in New Delhi in January 2013, and India's interventions at the IGC's 27th Session. 
domain and provide exclusive IP rights or related rights to its custodians. ${ }^{9}$ (Such attempts would scare hardline, and even moderate, non-demandeur countries and experts, justifiably or not.) But, at the same time, the approach holds that such TK or TCEs could attract other residual or calibrated rights, such as various forms of attribution rights and even reparation rights, or other remedial rights, especially for TK or TCEs that were diffused through theft and other forms of misappropriation where there was no free prior and informed consent of IPLCs.

It needs to be noted that the term "public domain" is a concept and expression particular to conventional IP. Pursuant to IP, information or knowledge in the public domain is free for use by all, and not subject of protection. However, "public domain" is not a synonym for "publicly available". The fact that a form of knowledge or information, including TK, TCEs or uses of GRs, is publicly available does not necessarily mean that such knowledge or information has the status of being in the public domain. It is, accordingly, critical to interrogate the process or terms by which it became publicly available.

\section{IGC stakeholder views on the approach}

The African Group, India, Indonesia, and the LMCs as a whole seem to share an understanding that the tiered or differentiated approach has the potential to assist with protection of TK and TCEs-in the variegated contexts of their diffusion and in ways that will guard against use of public domain arguments to undermine protection.

The EU, the United States, Japan, South Korea and Canada are engaging the approach with apprehension. Collectively, they have expressed concern over its potential effect on a range of issues, such as the "existing freedoms and the public domain" (WIPO 2014a, para. 53 [EU]), "innovation and creativity" (para. 41, [Japan]); and "inspiration" (para. 194, [Canada]). For countries within this category, terms such as "sacred", "secret", "widely diffused", and "publicly available"-terms which are associated with the tiered or differentiated approach-are, in the words of the Canadian position, "problematic from a certainty and clarity perspective" (para. 163), or, in the view of the EU, "open to further exploration" (para.167) and "open to interpretation" (para. 108). According to the US delegation, "publicly available and widely diffused TK and TCEs [do] not lend themselves to protection by exclusive rights" (WIPO, 2014a, para. 62). Canada's position is that "subject matter that was currently publicly available and that was not or was no longer protected

9 But consider the famous retort by Preston Hardison, a prominent member of the Indigenous Caucus at the IGC and official representative of the Tulalip Tribes of Washington State, who insists, analogously, that because Lady Gaga's music is widely diffused does not mean that she or her assigns should forgo their copyrights. Hardison rejects the genie-out-of-the-bottle argument if its objective is to facilitate appropriation of TK/TCE (see Hardison, 2016). 
by an intellectual property right (IPR) should not be protected" (para. 52) under IGC instruments. South Korea's view is that publicly-available, widely-diffused TK belongs to the public, and that retroactive protection would generate an unacceptable public cost (WIPO, 2014a, para. 78).

For its part, the IGC's Indigenous Caucus has adopted a reserved (and, in my view, prudent) attitude towards the tiered or differentiated approach, insisting that irrespective of the level of diffusion, whenever TK or a TCE is erroneously placed in the public domain, or is erroneously made publicly available, Indigenous Peoples' status as rights holders, and their entitlement to compensation or other appropriate remedies, should not be compromised. For the Indigenous Caucus, recognising the sacred nature of all TK and TCEs, not the level of diffusion, should be the starting point.

\section{Evolution of the tiered or differentiated approach}

The tiered or differentiated approach has evolved since its introduction in 2014. Initially, the approach identified five categories of TK and TCE, namely: (1) secret; (2) sacred; (3) closely held; (4) narrowly or partially diffused; and (5) widely diffused. However, these categories defy clear delineation, particularly in respect of:

- secrecy and sacredness of TK and TCEs; and

- diffusion.

\section{Complexities of "secrecy" and "sacredness"}

While secrecy is a feature of the sacredness of TK and TCEs, sacred aspects of TK and TCEs are sometimes conveyed in contexts where they are not taken as secret; and, vice versa. Secret aspects are sometimes conveyed in contexts where they are not perceived as sacred. This is so because of the fusion of intangible and tangible elements within tangible TK/TCE manifestations-as is seen in the example of bark paintings that is presented in the next section of this article.

\section{Complexities of the notion of "diffusion"}

A closely held, or narrowly or partially diffused, manifestation of TK or a TCE will require some evidentiary threshold regarding permissible level of diffusion-to eligible or ineligible "publics" - in terms of customary laws and protocols pertaining to the particular TK/TCE form. Also, there can be instances where even though a manifestation of TK or a TCE may be secret and sacred, it is also narrowly or partially diffused, or even widely diffused.

An important consideration is the fact that the degree of "diffusion" is not always a function of "publicness" - which is to say, diffusion is not necessarily a function of exposure or accessibility of the TK or TCE to members of the public, i.e., not necessarily a function of whether or not it is "in the public domain" or "publicly 
available", as per the terms used in the discussion above. ${ }^{10}$ Diffusion incorporates other factors and considerations. As stated in Oguamanam (2016), “[b]eyond being a matter of how 'well-known' as a feature of geographical application [or dispersal] and uptake, diffusion is perhaps a referential concept to what actually is known or legitimately disclosed in a specific TK context", making it possible for there to be "a widely or partially diffused TK that remains sacred and/or secret" (2016, p. 10). This observation is also true for TCEs. Also, the notion of diffusion can be logically scaled to include the extent to which a specific form of TK/TCE interacts with, influences, and/or is influenced by, other knowledge, innovations, and practices that are not strictly recognised as TK or a TCE. ${ }^{11}$ The concept of diffusion is not linear or presumptive. It involves articulation of the full scope of uses or applications of a TK and TCE, including the scope of its migration to, or transmission in, other knowledge contexts, as well as the range of its geographical uptakes or dispersals. This conception of diffusion, which is not reliant on publicness, is not mutually exclusive in respect of the conception grounded in publicness.

IGC deliberations seem to have not yet engaged with the full range of perspectives on the concept of diffusion - an illustration of the fact that the tiered or differentiated approach is still in its incubating stage. As the approach evolves, it can be expected that IGC stakeholders will adopt increasingly workable treatments of the realities of diffusion of TK and TCEs. One sign of increased engagement is the apparent move within the IGC towards four, and possibly even three-rather than the original conception of five-tiered categories.

\section{Crystallisation of four tiered categories}

While the IGC's tiered or differentiated approach to TK and TCEs remains a fluid concept, it currently appears to be crystallising around four overlapping (i.e., not mutually exclusive) categories, ${ }^{12}$ as illustrated in Figure 1 below:

- secret;

- sacred;

- narrowly diffused; and

- widely diffused.

10 It is noted that not all IPs are susceptible to the public domain counterpoise. For example, trade secrets remain exclusive property of the owner in perpetuity unless it status is compromised.

11 This is consistent with the view in anthropological circles that there is no knowledge that exists in isolation. And since knowledge is dynamic, that dynamism entails interaction across various knowledge systems as part of the process of knowledge creolisation and evolution. See Brown (1998).

12 The four-category framework dispenses with the "closely held" category, a highly vague concept. Arguably, however, the concept is captured under the "partially or narrowly diffused" category. 
Central premises of this move towards four categories are that:

- strong or exclusive rights should attach to secret and sacred TK and TCEs; and

- weaker forms of rights should attach to narrowly diffused and widely diffused TK and TCEs, since they are presumably available publicly, and some could also be said to be in the public domain. ${ }^{13}$

Figure 1: Four-category version of tiered or differentiated approach to TK and TCEs

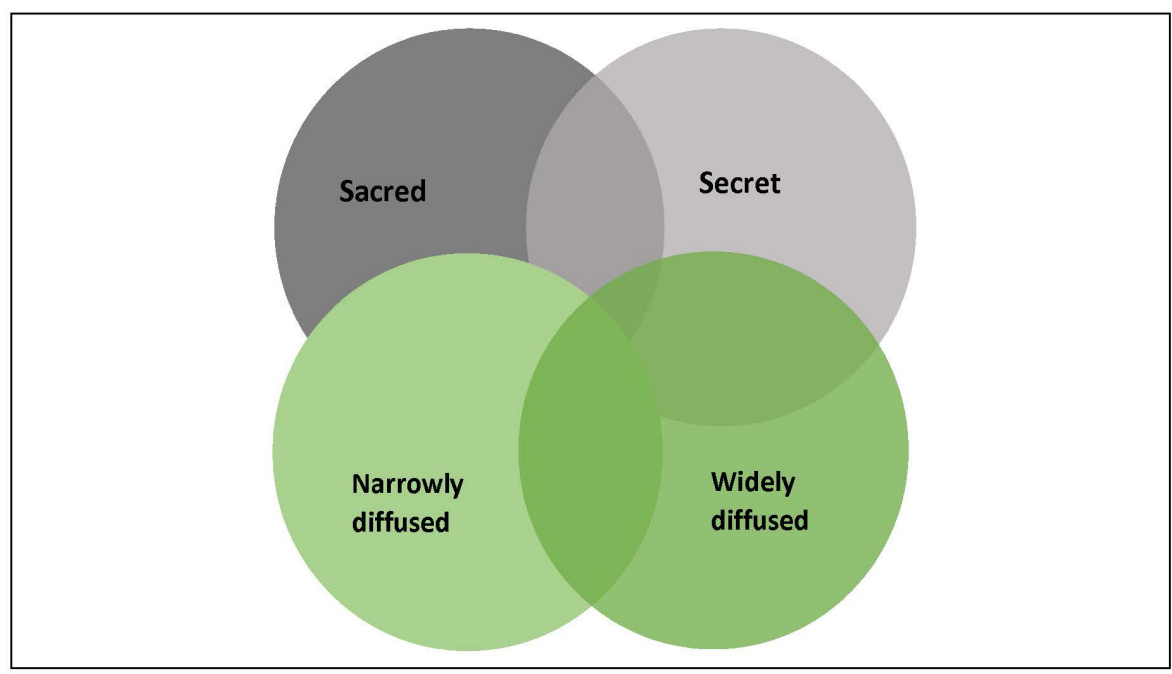

The four-category version of the tiered or differentiated approach, as shown in Figure 1, seeks to provide pragmatic recognition of the question of diffusion of TK and TCEs, while at the same time allowing IPLCs to make rights claims, the details of which can be customised according to the specific instance of TK or TCE and the corresponding IPLC's legal traditions and particular national context.

In the draft text on the tiered or differentiated approach, as it appeared in the Draft Articles on the protection of TK prepared for the IGC's 34th Session in 2017, the

13 There is need for a caveat here. One must not conflate the concept and ramifications of diffusion in the tiered and differentiated elaboration from other contexts. Wide diffusion is not an excuse for abandonment of rights given that the process through which a specific TK/TCE becomes widely diffused may be illegitimate as in cases of piracy or biopiracy. Therefore, to insist that wide diffusion puts TK in public domain border line with consequential weakening of rights is to reward abuses of TK through illegitimate acts of diffusion. 
wording of alternative 2 (“Alt 2") under Article 5 entitled "Scope of [and Conditions of] Protection", was as follows:

\section{Alt 2}

Member States [should/shall] safeguard the economic and moral interests of the beneficiaries concerning traditional knowledge as defined in this instrument, as appropriate and in accordance with national law, in a reasonable and balanced manner, and in a manner consistent with Article 14, in particular:

(a) Where the traditional knowledge is secret, whether or not it is sacred, Member States [should/shall] take legislative, administrative and/or policy measures, as appropriate, with the aim of ensuring that:

i. Beneficiaries have the exclusive and collective right to maintain, control, use, develop, authorize or prevent access to and use/ utilization of their traditional knowledge; and receive a fair and equitable share of benefits arising from its use.

ii. Beneficiaries have the moral right of attribution and the right to the use of their traditional knowledge in a manner that respects the integrity of such traditional knowledge.

(b) Where the traditional knowledge is narrowly diffused, whether or not it is sacred, Member States [should/shall] take legislative, administrative and/or policy measures, as appropriate, with the aim of ensuring that:

i. Beneficiaries receive a fair and equitable share of benefits arising from its use; and

ii. Beneficiaries have the moral right of attribution and the right to the use of their traditional knowledge in a manner that respects the integrity of such traditional knowledge.

(c) Where the traditional knowledge is not protected under paragraphs (a) or (b), Member States [should/shall] use best endeavors to protect the integrity of traditional knowledge, in consultation with beneficiaries where applicable. (WIPO, 2017a, boldfacing of text added by author)

The IGC's 2017 Draft Articles on the protection of TCEs contained analogous (though more elaborate) provisions, appearing as alternative 3, option 1, of Article 5 entitled "Scope of [Protection]/[Safeguarding]" (WIPO, 2017b).

The renewed IGC mandate for the 2018-2019 biennium, which began in March 2018, provided opportunities for further debate on and elaboration of the tiered or differentiated approach as a work in progress. The March 2019 revisions of the Draft Articles on TK and TCEs (revisions yet to be officially adopted at the time of finalisation of this article) further reviewed the concept of the tiered or differentiated approach as a work in progress. By the time that the IGC's 2018-2019 biennium 
draws to an end in June 2019, the tiered or differentiated approach will have evolved further, and, subject to the renewal of the IGC mandate by the WIPO General Assembly, exploration of the approach can be expected to morph onto the next biennium. ${ }^{14}$

\section{Examples relevant to a tiered or differentiated approach}

\section{Kente fabrics and designs in Ghana}

Ghana's kente fabrics and designs (Boateng, 2011) have over 4,000 years of history. Kente is largely linked with the pre-contact Akan people of the Asante (or Ashanti) Kingdom of West Africa, which once spread across territory that included not only parts of contemporary Ghana (Konadu, 2007) but also parts of today's countries of Côte D'Ivoire, Mali, Benin, Togo, Burkina Faso and Liberia. Originally, kente designs were associated mostly with Asante royalty, i.e., with the Asantehene (the spiritual ruler of the Asante Kingdom). Every design has a culturally rooted meaning and symbolism that depicts the Asante worldview, its rich creative imageries, its ethics of sacredness, and overall rich cultural heritage. As explained by Boateng (2011),

[T]he motifs used in Asante kente cloth weaving have specific names; however, the cloth is usually named for the colors and design of the background, which is often striped. As with Adinkara, kente is named for historic figures and events and also for Asante values. The design kyeretwie, or leopard, or leopard catcher, for example, symbolises courage, while aberewa ben, or "wise old woman," indicates the respect accorded older women in Asante society. Another design is named Oyokoman named for the Oyoko clan. One especially rich and prestigious version of these and other designs is called adweneasa or adwenasa, a name that refers to the weaver's skills. (Boateng, 2011, p. 23)

Kente has followed plural pathways of diffusion. ${ }^{15}$ The current reality of kente's diffusion is that it is no longer exclusive to Asante royalty. Rather, kente fabric is now available to whoever can afford it, among the Asante, in Ghana as a whole, among other Africans, and indeed, globally. Yet it is, in part, because of this global diffusion, rather than despite it, that kente remains, unquestionably, a symbol of both pre-colonial Asante identity and post-colonial Ghana's national character. Another aspect of kente's diffusion relates to transformation of its processes of production. Earlier kente fabrics were made of GRs, specifically straws from species of bamboo and raffia endemic to regions within the Asante Kingdom (Schneider, 1987). Today, kente fabrics are typically made of silk or cotton, or even industrial synthetic

14 The 40th Session of the IGC, which was held June 17-21 2019, produced the latest modified texts of the tiered or differentiated approach to TK/TCEs, which will be used for continuing negotiation over the 2021-2021 biennium.

15 They include Asante/Akan (central Ghana); Gonja (northern Ghana); and Ewe (southeastern Ghana). 
materials of varying quality, including rayon. And kente designs can, today, be found in broadloom cloth, ${ }^{16}$ in various forms of clothing and fashion accessories, and even in non-textile items such as stationary, i.e., in products falling outside kente's original and historic limitations and applications. But those uses do not extend beyond kente's characteristics as a tangible piece of creative work. To the "uninitiated", the uses do not include kente's intangible elements and symbolisms which remain exclusively relevant to the Asante.

\section{Aboriginal bark-painting in Arnhem, Australia}

Aboriginal bark paintings in Arnhem, Australia, are a fusion of the sacred, the intangible, and the tangible, in a manner that engages plural layers of diffusion. The paintings are associated with the Aboriginal peoples of the Arnhem region of Australia's Northern Territory. Case law has recognised bark paintings as creative works that are associated with sacred dreaming images and the creation stories of exclusive cultural communities (see the 1994 decision in Australia's Milpurrurru v Indofurn Pty Ltd case). Aboriginal bark artists operate within an exclusive cultural environment. Their work is based on and inspired by collectively-held traditional and sacred cultural heritage, the secret aspects of which are only known to a limited number of members of a specific clan.

When deploying or working with those elements of collectively-held cultural heritage, the artists effectively act as fiduciaries or cultural agents, playing intermediary roles between members of their communities and outsiders in respect of the terms of use, or access to, their scared paintings (see Milpurrurru $v$ Indofurn Pty Ltd [1994]). Yet despite the deeply embedded sacred cultural symbols, rituals, and other forms of intangibility associated with bark paintings, they have gradually become quintessential, highly tangible public works of Aboriginal art, serving as integral aspects of Australia's national identity and brand. Aboriginal bark-painting images are present in Australia in ubiquitous adaptations in designs for, inter alia, postage stamps, calendars, tourist information, certified documentations in the Australian National Gallery, and the folio of Aboriginal art published by the Australian Information Service (see Milpurrurru v Indofurn Pty Ltd [1994], and Blakeney, 1995). Unequivocally, bark paintings are widely diffused as the proud symbol of Australia's national heritage premised on its sacred and rich Indigenous historiography and origins. Those sacred aspects associated with bark paintings as Indigenous heritage constitute aspects of their intangible essence and associated meaning-making that inalienably and residually link them to their Indigenous creators.

\section{Cowichan weaving in North America}

Cowichan weaving, practised by the Cowichan grouping of Coast Salish Indigenous Peoples in North America's Pacific Northwest (the province of British Columbia

16 For insight on the technological diffusion of kente production, see Boateng (2011, pp. 27-30). 
in Canada, and Washington State in the US), is another example of TK/TCE with multiple layers of diffusion and variegated degrees of sacredness or symbolism.

According to Stopp (2012), Cowichan weaving involves the primordial skill of being able to transform plant and animal fibre materials into woven textiles products. The pre-colonial Coast Salish bred special dogs for their hair as a core GR used in weaving blankets and other functional items for protection against harsh weather conditions. Over time, following colonial encounter, other materials such as sheep wools and synthetic fibres were, and still are, used in Cowichan weaving. As well, the weaving practice has been extended and adapted in order to make sweaters, a Europeanorigin article of clothing which, before colonial encounter, was not part of Aboriginal dress in the European form and design. Yet weaving remains a pivotal aspect of the customary laws and practices and the heritage of the Coast Salish. Similar to kente's global diffusion, the Cowichan sweater still retains its historical and cultural symbolisms even as it serves as an internationally-consumed product that provides an anchoring point for the Cowichan people's participation in the global economy (Stopp, 2012). Among other things, the symbolic aspects of Cowichan sweaters designate the intricate nature of relationships and dependencies across life forms, art and creativity as a mirror of their intangible essence in Coast Salish experience. Cowichan sweaters were prominent in Canada's showcasing during the 2010 Winter Olympics in Vancouver, ${ }^{17}$ and are marketed globally as "warm, weatherproof, sturdy, serviceable, durable for outdoor pursuits [and] one of the world's most distinctive sweater types" (Stopp, 2012, p. 82).

\section{Analysis and conclusions}

\section{Secrecy, sacredness, diffusion, and the public domain}

Across the three examples outlined above, different degrees of secrecy and sacredness can be identified. Available evidence demonstrates that the Aboriginal bark paintings in Arnhem, Australia, are considered sacred, even up to the present time. Kente fabrics and designs, meanwhile, were once considered highly sacred but, over time, have had their sacredness somewhat diluted. As with bark paintings, the sacredness of kente, and the symbolisms of the designs, are sites of complex meaning-making that most easily resonate among the initiated within an exclusive cultural core.

As products and processes, the rituals and symbolisms associated with Aboriginal bark-painting and kente fabrics/designs largely designate their intangible aspects, which are outside the consciousness of the members of the public who acquire them

17 See Scassa (2015), who argues that appropriation of Indigenous cultural heritage, as exemplified by (1) a UK designer's copying of an Inuit shaman's robe and (2) Canadian retailer the Hudson's Bay Company's (HBC's) procurement of non-Cowichan-made versions of Cowichan sweaters for sale during the Vancouver Winter Olympics unravels "the disconnect between IP laws and indigenous cultural property". 
only as products. The interest of non-Aboriginal or non-Indigenous patrons of bark paintings and kente lies in the products' physical (tangible) qualities. ${ }^{18}$ In such contexts, there is little regard for the products' spiritual and other intrinsic cultural ramifications (i.e., the intangible components). ${ }^{19}$ With regard to Cowichan weaving in North America, the intangible aspects of its culturally-rooted spirituality and symbolism rarely take prominence.

In respect of diffusion, the three examples provided above demonstrate that:

- it is possible to have sacred and/or secret forms of TK or TCE that are narrowly diffused, or-even more important for the present analysiswidely diffused; and

- diffusion is not exclusively determined by geographic dispersal or public accessibility. For example, kente designs and bark arts are now manifested in non-traditional applications, such as in stationary and/or in other sites (e.g., postage stamps, tourist ornaments, and miscellaneous accessories) where their aesthetic appeals are leveraged to create non-traditional products.

In respect of the public domain or public availability, the three examples show that:

- the less a form of TK/TCE retains its spiritual and cultural claims, the more it is likely to resonate with claims to the public domain (and consequently also resonate with weaker rights claims, or weaker claims of control, by its custodians); and

- in order to fully grapple with the notion of a tiered or differentiated approach, it is important to be conscious of the interwoven nature of the tangible and the intangible in TK and TCEs, and to be conscious of how each element changes our understanding of the public domain. For example, a form of TK or TCE may be publicly available, and may even be said to be in the public domain, while at the same time its sacred and intangible components are neither publicly available nor in the public domain.

\section{Interfaces between GRs and TK/TCEs}

Each of the three examples demonstrates that the association of GRs with TK and TCEs is not limited to the uses of GRs in the typical contexts of traditional medicine and agriculture (with corresponding associations with biodiversity and

18 The global dispersal and replication of kente on an industrialised scale via production in China demonstrates the commercial usurpation and appropriation of kente that de-links it from its cultural essence. The same has been found to be true in a number of litigations in Australia around bark paintings. Notably, in the Milpurrurru case, non-Aboriginal Australian businesspeople commissioned a Vietnamese company to manufacture carpets using designs from bark paintings (by eight highly regarded Aboriginal artists), with the carpets imported, distributed and marketed in Australia without regard to the sacredness of the bark paintings from which they were adapted. See Milpurrurru v Indofurn Pty Ltd [1994].

19 See Milpurrurru v Indofurn Pty Ltd [1994]. 
environmental conservation). Rather, the interfaces between GRs and TK and TCEs also encompass other sites of traditional creativity grounded in creative art forms, ${ }^{20}$ as evidenced by the kente-weaving and the bark-painting, both of which depend in a primary manner on GRs.

\section{Evidentiary threshold}

Determining the status of a specific manifestation of TK or TCE in relation to each, or more than one, of the four differentiated categories listed above will be contingent upon the evidentiary threshold of the TK/TCE's diffusion or lack thereof. If the tiered or differentiated approach is to attain its objective of enhancing clarity, much will depend on deployment of the evidentiary threshold across each of the four categories of differentiation - secrecy, sacredness, narrow diffusion, wide diffusionand across the areas of overlap among these four categories. Whether, and to what extent, a form of TK or TCE is secret, sacred, partially diffused, or widely diffused, will always be context- and subject-specific inquiries: context-specific with respect to the IPLC custodians or owners of the TK/TCE, and with respect to the relevant IPLC's customary laws and protocols, and subject-specific with respect to the type of TK/TCE at issue. It will also need to be acknowledged that context and subject can mutually interact. Moreover, in addition to documentation of the experiences of the relevant IPLC(s), documentation of the experiences of external users of the TK and TCE will be important, as an evidentiary matter, to establishing the extent of diffusion or lack thereof.

\section{Role of IPLCS}

Establishment of a credible evidentiary threshold with regard to diffusion for a particular manifestation of TK or TCE will require nuanced and sophisticated understanding of the details of the nature of the knowledge and of the layers of relationships implicated — as well as understanding of the nature and boundaries of roles assigned to stakeholders in the specific cultural context. These forms of evidence-gathering cannot be legislated at global level in a forum such as the IGC, nor even at national levels. IPLCs are the only credible custodians of their TK and TCEs, which are aspects of their self-determination and sovereignty (Coombe, 1998b; Hardison, 2016; Oguamanam, 2014).

IPLC representation at the IGC is sub-optimal and constrained. ${ }^{21}$ And even if IPLCs were to be adequately represented at the IGC, the forum could not presume to have

20 Kente, Aboriginal bark-painting, and Cowichan weaving demonstrate the overlap of TK and TCEs with GRs and their interface with IP regimes such as copyrights, designs and trademarks-providing counterpoints to the tendency to focus GR discussions exclusively on the patent regime, i.e., the tendency to imply that efforts at patenting of innovation in life sciences (biotechnology, agriculture, chemicals, medicines, etc.) are the only sites where IP is implicated in GRs and associated TK.

21 This issue of IPLC participation in IGC deliberations has been problematic from the beginning, owing to the fact that its delegation relies on voluntary funding support from Member States. See WIPO (n.d.b). 
full legitimacy in respect of detailing practical and evidentiary issues necessary to make determinations on the tiered or differentiated status of a specific manifestation of TK or TCE (see Anaya, 2016; Hardison, 2016). TK and TCEs are inherently dynamic and responsive (Posey \& Dutfield, 1996), and the same is true of the undergirding customary laws, protocols, and practices of the IPLCs linked to manifestations of TK and TCEs. In formulating the details of operationalisation of the tiered or differentiated approach in national contexts, constituent IPLCs will need to provide the pathways for how their customary laws and protocols are engaged.

\section{IGC views on roles of IPLCs as beneficiaries}

The IGC's Indigenous Caucus, most non-demandeur members and experts, and some of the members of the LMCs group, have made it clear that they see IPLCs as the primary beneficiaries of IP protection TK and TCEs. ${ }^{22}$ However, the African Group, and the majority of members of the LMCs group, are insisting that national governments/states are also legitimate beneficiaries of the protection of TK/TCEsor, put more technically, that they are legitimate beneficiaries of any instrument(s) resulting from the IGC.

As such, Member States will need to be proactive in the IGC in formulating requisite operational details of the tiered or differentiated approach. The nature of the relationship between national governments and IPLCs is largely a factor of colonial relations (Anaya, 2004). In colonial states-for example, Canada, the US, Australia, New Zealand, and elsewhere where the settler did not withdraw-such relationships disentitle states from any claims to ownership of, or assumption of beneficiary status in relation to, TK and TCEs vis-à-vis Indigenous Peoples. The same cannot not be said with any degree of definitiveness in many postcolonial states in Africa and elsewhere in the Global South where Indigenous Peoples and various categories of IPLCs today constitute the dominant cultures and societies (Coombe, 1998b). Regardless of the nature of each national government's relation to Indigenous Peoples — and, by extension, to manifestations of TK and TCE — it is undeniable that the customary protocols and practices of IPLCs will be crucial in implementing the tiered or differentiated approach at both national and sub-national levels.

22 Article 4, alternative 1, in The Protection of Traditional Knowledge: Draft Articles, drafted for the IGC's 37th Session, provides as follows: "Beneficiaries of this instrument are indigenous [peoples] and local communities who hold [protected] traditional knowledge" (WIPO, 2018a). 


\section{References}

\section{Primary sources}

Anaya,J. S. (2016). Technical Review of Key Intellectual Property-Related Issues of the WIPO Draft Instruments on Genetic Resources, Traditional Knowledge and Traditional Cultural Expressions by Professor James Anaya (December 6, 2016). WIPO/GRTKF/IC/33/INF/9. Information document submitted by the Secretariat of the United Nations Permanent Forum on Indigenous Issues. For IGC Thirty-Third Session, Geneva, February 27 to March 3, 2017. Retrieved from http://www.wipo.int/meetings/en/doc details.jsp?doc id=360462

Convention on Biological Diversity (CBD). (2010). The Nagoya Protocol on Access and Benefit-Sharing. Retrieved from https://www.cbd.int/abs

CBD. (n.d.) Article 15: Access to Genetic Resources. Retrieved from https://www.cbd.int/ convention/articles/default.shtml?a=cbd-15

CBD. (n.d.). Bonn Guidelines. Retrieved from https://www.cbd.int/doc/publications/cbdbonn-gdls-en.pdf

CBD. (n.d.). Article 8(j): Traditional Knowledge, Innovations and Practices. Retrieved from https://www.cbd.int/traditional

Food and Agriculture Organisation of the United Nations (FAO). (2001). International Treaty on Plant Genetic Resources for Food and Agriculture. Retrieved from http://www. fao.org/plant-treaty/en/

Hardison, P. (2016). Response to WIPO Indigenous Panel on Outstanding/Pending Issues in the IGC Draft Articles on the Protection of Traditional Knowledge: Indigenous Peoples' and Local Communities' Perspectives (November 28, 2016). IGC Thirty-Second Session, Geneva, November 28 to December 2, 2016 (on file with author).

Intergovernmental Committee (IGC). (n.d.). World Intellectual Property Organisation (WIPO). Retrieved from http://www.wipo.int/tk/en/igc

McCook, W. (2014a). Traditional Knowledge and Traditional Cultural Expressions: Certain Suggested Cross-Cutting Issues - Non-Paper Prepared by the IGC Chair, His Excellency, Ambassador Wayne McCook. For IGC Twenty-Seventh Session, March 24 to April 4, 2014. Retrieved from http://www.wipo.int/export/sites/www/tk/en/igc/pdf/igc_27_issues.pdf

McCook, W. (2014b). Traditional Knowledge and Traditional Cultural Expressions: Certain Suggested Cross-Cutting Issues (March 12, 2014). WIPO/GRTKF/IC/INF/10. Document prepared by the Chair of the Intergovernmental Committee on Intellectual Property and Genetic Resources, Traditional Knowledge and Folklore, His Excellency, Ambassador Wayne McCook. Retrieved from http://www.wipo.int/meetings/en/doc_details.jsp?doc_id=269068 Milpurrurru v Indofurn Pty Ltd [1994] 130 ALR 659 (Federal Court of Appeal) (Austl.).

Standing Committee on the Law of Patents. (n.d.). Website. World Intellectual Property Organisation (WIPO). Retrieved from http://www.wipo.int/policy/en/scp/

UN. (1992). Convention on Biological Diversity (CBD). Retrieved from https://www.cbd. int/convention 
World Intellectual Property Organisation (WIPO). (2014a). Report (July 2, 2014). WIPO/ GRTKF/IC/27/10. IGC Twenty-Seventh Session, Geneva, March 24-April 4, 2014. Retrieved from https://www.wipo.int/edocs/mdocs/tk/en/wipo grtkf ic 27/wipo grtkf ic 27 10.pdf

WIPO. (2014b). The Protection of Traditional Knowledge: Draft Articles (June 2, 2014). WIPO/GRTKF/IC/28/5. For IGC Twenty-Eighth Session, Geneva, July 7 to 9, 2014. Retrieved from https://www.wipo.int/edocs/mdocs/tk/en/wipo grtkf ic 28/wipo grtkf ic 28 5.pdf

WIPO. (2014c). The Protection of Traditional Cultural Expressions: Draft Articles (June 2, 2014). WIPO/GRTKF/IC/28/6. For the IGC Twenty-Eighth Session, Geneva, July 7 to 9, 2014, Retrieved from WIPO. (2014b). The Protection of Traditional Knowledge: Draft Articles (June 2, 2014). WIPO/GRTKF/IC/28/5. Prepared for the IGC Twenty-Eighth Session, Geneva, July 7 to 9, 2014, Retrieved from https://www.wipo.int/edocs/mdocs/tk/en/ wipo grtkf ic 28/wipo grtkf ic 28 5.pdf

WIPO. (2015). Matters Concerning the Intergovernmental Committee on Intellectual Property and Genetic Resources, Traditional Knowledge and Folklore. Agenda Item 17, Assemblies of Member States of WIPO Fifty-Fifth Session, October 5 to 14,2015. Retrieved from http://www.wipo.int/export/sites/www/tk/en/igc/pdf/igc mandate 1617.pdf

WIPO. (2016a). Report (September 23, 2016). Thirtieth Session Geneva, May 30 to June 3, 2016. WIPO/GRTKF/IC/30/10 Retrieved from http://www.wipo.int/edocs/mdocs/tk/en/ wipo grtkf ic 31/wipo grtkf ic 31 ref 30 10.pdf

WIPO. (2016b). The Protection of Traditional Knowledge: Draft Articles, Rev. 2 (in Annexure) (October 3, 2016). WIPO/GRTKF/IC/32/4. For IGC Thirty-Second Session, Geneva, November 28 to December 2, 2016. Retrieved from http://www.wipo.int/edocs/ mdocs/tk/en/wipo grtkf ic 32/wipo grtkf ic 32 4.pdf

WIPO. (2016c). Informal Briefing Notes: Perspectives and Experiences on Tiered Approach to the Protection of Traditional Knowledge: Scope of Protection, Exceptions and Limitations (November 3, 2016) (on file with author). WIPO. (2017a). The Protection of Traditional Knowledge: Draft Articles (March 15, 2017). WIPO/GRTKF/IC/34/5. For IGC ThirtyFourth Session, Geneva, June 12-16, 2017. Retrieved from https://www.wipo.int/meetings/ en/doc details.jsp?doc id=368218

WIPO. (2017b). The Protection of Traditional Cultural Expressions: Draft Articles (June 15, 2017). WIPO/GRTKF/IC/34/8. IGC Thirty-FourthSession, Geneva, June 12-16, 2017. Retrieved from https://www.wipo.int/edocs/mdocs/tk/en/wipo grtkf ic 34/wipo grtkf ic 34 8.pdf

WIPO. (2018a). The Protection of Traditional Knowledge: Draft Articles (June 26, 2018). WIPO/GRTKF/IC/37/4. For IGC Thirty-Seventh Session, Geneva, August 27 to 31, 2018. Retrieved from https://www.wipo.int/edocs/mdocs/tk/en/wipo grtkf ic 37/wipo grtkf ic 37 4.pdf

WIPO. (2018b). The Protection of Traditional Cultural Expressions: Draft Articles (June 27, 2018). WIPO/GRTKF/IC/37/5. Drafted for IGC Thirty-Seventh Session, Geneva, August 27 to 31, 2018. Retrieved from https://www.wipo.int/meetings/en/doc details. jsp?doc id=409623 
WIPO. (n.d.a). Draft substantive Patent Law Treaty. Retrieved from http://www.wipo.int/ patent-law/en/draft splt.htm

WIPO. (n.d.b). Case for support: Promoting effective participation of indigenous and local communities. WIPO Voluntary Fund for Accredited Indigenous and Local Communities. Retrieved from http://www.wipo.int/export/sites/www/tk/en/igc/pdf/flyer_vol_fund.pdf

\section{Secondary sources}

Adewopo, A., Chuma-Okoro, H., \& Oyewuni, A. (2014). A consideration of communal trademarks for Nigerian leather and textile products. In J. De Beer, C. Armstrong, C. Oguamanam, \& T. Schonwetter (Eds.), Innovation and intellectual property: Collaborative dynamics in Africa (pp. 109-131. Cape Town: UCT Press.

Akinbogun, T. L., \& Ogunduyile, S. R. (2009). Crafts engagement in the economic survival of South-Western Nigerian rural women. Journal of Enterprising Communities: People and Places in the Global Economy, 3(2), 217-234. https://doi.org/10.1108/17506200910960897

Anaya,J. S. (2004). Indigenous peoples in international law (2nd ed.). Oxford: Oxford University Press.

Arewa, O. B. (2004). Piracy, biopiracy, and borrowing: Culture, heritage, and the globalization of intellectual property. Case Research Paper Series in Legal Studies. Working Paper No. 04-19. Retrieved from https://papers.ssrn.com/sol3/papers.cfm?abstract id=596921

Arezzo, E. (2007). Struggling around the natural divide: The protection of tangible and intangible Indigenous property. Cardozo Arts and Entertainment Law Journal, 25(1).

Bala, A. (2011). Traditional knowledge and intellectual property rights: An Indian perspective. https://doi.org/10.2139/ssrn.1954924

Battiste, M. (Ed.) (2000). Reclaiming Indigenous voices and vision. Vancouver: UBC Press.

Blakeney, M. (1995). Milpurrurru \& Ors v Indofurn \& Ors: Protecting expressions of Aboriginal folklore under copyright law. Murdoch University Electronic Journal of Law, 2(1).

Boateng, B. (2011). The copyright thing doesn't work here: Adinkara and Kente cloth and intellectual property in Ghana. Minneapolis: University of Minnesota Press.

https://doi.org/10.5749/minnesota/9780816670024.001.0001

Brown, M. F. (1998). Can culture be copyrighted? Current Anthropology, 39(2), 193-222. https://doi.org/10.1086/204721

Brown, M. F. (2004). Who owns native culture? Cambridge, MA: Harvard University Press.

Coombe, R. J. (1998a). The cultural life of intellectual properties: Authorship, appropriation and the law. Durham, NC: Duke University Press. https://doi.org/10.1215/9780822382492

Coombe, R. J. (1998b). Intellectual property, human rights and sovereignty: New dilemmas in international law posed by the recognition of Indigenous knowledge and the conservation of biological diversity. Indiana Journal of Global Legal Studies 6(1), 59-115. 
De Beer, J., Oguamanam, C., \& Schonwetter, T. (2014). Innovation, intellectual property, and development narratives in Africa. In J. De Beer, C. Armstrong, C. Oguamanam, \& T. Schonwetter (Eds.), Innovation and intellectual property: Collaborative dynamics in Africa (pp. 1-31). Cape Town: UCT Press.

De Sousa Santos, B. (Ed.) (2007). Another knowledge is possible: Beyond Northern epistemologies. London: Verso.

De Sousa Santos, B., Nunes, J. A., \& Meneses, M. P. (2007). Introduction: Opening up the canon of knowledge and recognition of difference. In B. De Sousa Santos (Ed.) (2007). Another knowledge is possible: Beyond Northern epistemologies (pp. xxix-1xii). London: Verso.

Elahi, S., \& De Beer, J., (2013). Knowledge and innovation in Africa: Scenarios for the future. With D. Kawooya, C. Oguamanam, N. Rizk, and the Open AIR Network. University of Cape Town and University of Ottawa: Open African Innovation Research (Open AIR).

Helfer, L. H. (2004). Regime shifting: The TRIPS Agreement and new dynamics of international intellectual property lawmaking. Yale Journal of International Law, 29(1), 1-83. https://doi.org/10.2139/ssrn.459740

Jayangakula, K.(n.d.). The protection of the expression of folklore and copyright law. Retrieved from https://www.academia.edu/3423284/The Protection of the Expression of Folklore and Copyright Law

Konadu, K. B. (2007). Indigenous medicine and knowledge in African society. London: Routledge. Kuruk, P. (1999). Protecting folklore under modern intellectual property regimes: A reappraisal of the tensions between individual and communal rights in Africa and the United States. American University Law Review, 48(4), 769-849.

Maiwada, S., Dutsenwai, S. A., \& Waziri, M. Y. (2012). Cultural industries and wealth creation: The case of traditional textile industry in Nigeria. American Journal of Contemporary Research, 2(5), 159-165.

Maskus, K. E., \& Reichman, J. H. (2004). The globalization of private knowledge goods and the privatization of global public goods. Journal of International Economic Law, 7(2), 279-230. https://doi.org/10.1093/jiel/7.2.279

Maskus, K. E., \& Reichman, J. H. (Eds.) (2005). International public goods and transfer of technology under a globalized intellectual property regime. Cambridge, UK: Cambridge University Press. https://doi.org/10.1017/CBO9780511494529

May, C., \& Sell, S. (2005). Intellectual property rights: A critical history. Boulder, CO: Lynne Rienner Publishers.

Memmi, A. (1990). The colonizer and the colonized. London: Earthscan.

Mgbeoji, I. (2001). Patents and traditional knowledge of the uses of plants: Is a communal patent regime part of the solution to the scourge of bio piracy? Indiana Journal of Global Legal Studies, 9(I), 163-186.

Mgbeoji, I. (2006). Global biopiracy: Patents, plants, and Indigenous knowledge. Vancouver: UBC Press. 
Mutua, M. (2011). Savages, victims, and saviors: The metaphor of human rights. Harvard Law Review, 412(1), 201-244.

Oguamanam, C. (2007). Agro-biodiversity and food security: Biotechnology and traditional agricultural practices at the periphery of international intellectual property regime complex. Michigan State Law Review, 2007, 215-255.

Oguamanam, C. (2008). Local knowledge as trapped knowledge: Intellectual property, culture, power and politics. Journal of World Intellectual Property, 11(1), 29-57.

https://doi.org/10.1111/j.1747-1796.2008.00333.x

Oguamanam, C. (2012). Intellectual property in global governance: A development question. New York: Routledge.

Oguamanam, C. (2014). Indigenous Peoples' rights at the intersection of human rights and intellectual property rights. Marquette Intellectual Property Law Review, 18(2), 261-295.

Oguamanam, C. (2015). Pressuring 'suspect orthodoxy': Traditional knowledge and the patent system. In M. Rimmer (Ed.), Indigenous intellectual property: A handbook of contemporary research (pp. 313-333). Cheltenham, UK: Edward Elgar.

https://doi.org/10.4337/9781781955901.00024

Oguamanam, C. (2016). Tiered or differentiated approach to traditional knowledge: Insights for understanding the operations of the concept and evidentiary thresholds. Presentation to WIPO-IGC Seminar on Traditional Knowledge and Intellectual Property (Nov. 24-25, 2016). Retrieved from http://www.wipo.int/edocs/mdocs/tk/en/wipo iptk ge 2 16/wipo iptk ge 216 presentation 7oguamanam.pdf

Oguamanam, C. (2017). Ramifications of WIPO IGC for IP and development. In D. F. Robinson, A. Abdel-Latif, \& P. Roffe (Eds.), Protecting traditional knowledge: The WIPO Intergovernmental Committee on Intellectual Property and Genetic Resources, Traditional Knowledge, and Folklore (pp. 339-346). New York: Routledge.

Oguamanam, C. (2018a). Wandering footloose: Traditional knowledge and the public domain revisited. Journal of World Intellectual Property, 21(5-6), 306-325.

https://doi.org/10.1111/jwip.12096

Oguamanam, C. (2018b). Tiered or differentiated approach to traditional knowledge and traditional cultural expressions: The evolution of a concept. CIGI Papers No. 185. Waterloo, ON: Centre for International Governance Innovation (CIGI).

https://doi.org/10.2139/ssrn.3265807

Okediji, R.L. (2017). Negotiating the public domain in an international framework for genetic resources, traditional knowledge and traditional cultural expressions. In D. F. Robinson, A. Abdel-Latif, \& P. Roffe (Eds.), Protecting traditional knowledge: The WIPO Intergovernmental Committee on Intellectual Property and Genetic Resources, Traditional Knowledge, and Folklore (pp. 141-172), New York: Routledge.

Okediji, R. L. (2018). Traditional knowledge and the public domain. CIGI Papers No. 176. Waterloo, ON: Centre for International Governance Innovation (CIGI). Retrieved from https:/www.cigionline.org/sites/default/files/documents/Paper\%20no.176.pdf 
OseiTutu, J. J. (2011). A sui generis regime for traditional knowledge: The cultural divide in intellectual property law. Marquette Intellectual Property Law Review, 15(1), 147-215.

Posey, D. A., \& Dutfield, G. (1996). Beyond intellectual property: Toward traditional resource rights for Indigenous Peoples and local communities. Ottawa: International Development Research Centre (IDRC). Retrieved from https://www.idrc.ca/en/book/beyond-intellectualproperty-toward-traditional-resource-rights-indigenous-peoples-and-local

Raustiala, K. (2007). Density and conflict in international intellectual property law. UC Davis Law Review, 40(3), 1021-1038.

Reichman, J. H. (2009). Intellectual property in the twenty-first century: Will the developing countries lead or follow? Houston Law Review, 46(4), 1115-1185.

Robinson, D. F. (2010). Confronting biopiracy: Challenges, cases, and international debates. London: Routledge. https://doi.org/10.4324/9781849774710

Robinson,D.F.,Abdel-Latif,A.,\& Roffe,P.(Eds.) (2017).Protecting traditionalknowledge:The WIPO Intergovernmental Committee on Intellectual Property and Genetic Resources, Traditional Knowledge, and Folklore. New York: Routledge. https://doi.org/10.4324/9781315666358

Scassa, T. (2015, November 26). Copyright of Inuit robe highlights gaps in Canadian legal framework [Blog post]. Teresa Scassa Blog. Retrieved from http://www.teresascassa.ca/index. php?option=com $\mathrm{k} 2 \&$ view=item\&id $=200 \% 3$

Schneider, J. (1987). The anthropology of cloth. Annual Review of Anthropology, 16, 409-448. https://doi.org/10.1146/annurev.an.16.100187.002205

Stiglitz, J. E. (1999). Knowledge as a global public good. Oxford: Oxford University Press.

Stopp, M. P. (2012). The Coast Salish knitters and the Cowichan sweater: An event of national historic significance. Material Culture Review/ Revue de la culture matérielle, 76, 9-29. Retrieved from https://journals.lib.unb.ca/index.php/MCR/article/view/21406/24805

Wiessner, S. (1999). Rights and status of Indigenous Peoples: A global comparative and international legal analysis. Harvard Human Rights Journal, 12.

Wiessner, S., \& Graham, L. (2011). Indigenous sovereignty, culture, and international human rights law. South Atlantic Quarterly, 110(2), 403-427.

https://doi.org/10.1215/00382876-1162516

$\mathrm{Yu}$, P. K. (2007). International enclosure, the regime complex, and intellectual property schizophrenia. Michigan State Law Review, 2007(1), 1-33. 